
\title{
25 Research Soure \\ Relationship Between Obstetric Complications in Women Undergoing IVF with PCOS: A Retrospective Cohort Study
}

R Muharam ( $\nabla$ rmuharam@yahoo.com )

Prasetyo Yohanes Danang

Universitas Indonesia Fakultas Kedokteran https://orcid.org/0000-0001-6989-7635

Mila Maidarti

Universitas Indonesia Fakultas Kedokteran

Achmad Kemal Harzif

Universitas Indonesia Fakultas Kedokteran

Gita Pratama

Universitas Indonesia Fakultas Kedokteran

\section{Budi Wiweko}

Universitas Indonesia Fakultas Kedokteran

Andon Hestiantoro

Universitas Indonesia Fakultas Kedokteran

\section{Research}

Keywords: Polycystic Ovary Syndrome (PCOS), In Vitro Fertilization (IVF), infertility, obstetric complications.

Posted Date: August 2nd, 2020

DOI: https://doi.org/10.21203/rs.3.rs-49457/v1

License: (c) (i) This work is licensed under a Creative Commons Attribution 4.0 International License.

Read Full License 


\section{Abstract}

Background: Polycystic ovary syndrome (PCOS) is a highly prevalent endocrine and metabolic disorder. One of its complications is infertility. In Vitro Fertilization (IVF) is one of the alternatives to the problem. However, there are no study describing the differences in obstetric complications of PCOS patients undergoing IVF compared to other patients. This study aims to determine the relationship of obstruction complications in women undergoing IVF programs with PCOS.

Methods: This was a retrospective cohort study conducted at Cipto Mangunkusumo National General Hospital on 2013-2019. The study subjects were all women aged over 18 years who underwent IVF programs without other gynecological abnormalities besides PCOS. The outcomes in this study were obstetric complications in the form of abortion. Analysis is done by using cox-regression to get the value of Hazard Ratio (HR) after controlling for confounding factors.

Results: This study included 355 women, of whom 72 had PCOS (20.3\%). Complications found in subjects with PCOS were preterm found in (2.78\%), abortion (9.72\%) and ectopic pregnancy $(1.39 \%)$. No association was found between PCOS and abortion in women undergoing IVF programs ( $p$-value $>0.05$ ). Interaction between PCOS and cleavage ratio $<6$ had higher probability of having abortion in women undergoing IVF program obtained. (RR: 7.32, 95\% Cl: 2.10-25.45, P-value: 0.002).

Conclusion: PCOS does not affect the occurrence of abortion in women undergoing IVF program.

\section{Plain English Summary}

Polycystic ovary syndrome (PCOS) is a major health problem with high incidence in women. PCOS appears with its related complications, such as infertility and increased risk of pregnancy complications. Some of most prevalent obstetric complications related to PCOS are early pregnancy loss, ectopic pregnancy, and preterm birth. In vitro fertilization (IVF) is a method of managing infertility through fertilization outside uterus. However, there was yet a study of obstetric complications in PCOS patients undergoing IVF in Indonesia. A study was carried out on women undergoing IVF program in Indonesia. A total of 355 women, 72 of which had PCOS, were included in the study. It was found that PCOS patients undergoing IVF program did not have higher risk of having preterm labor, abortion, nor ectopic pregnancy compared to normal population. Therefore, IVF should remain as one of infertility treatment in PCOS patients, without any added obstetric complications risk.

\section{Introduction}

Polycystic ovary syndrome (PCOS) or polycystic ovarian syndrome is broadly defined based on the Rotterdam consensus criteria of finding at least 2 of the 3 disorders in the form of; (1) at least one ovary has 12 or more follicles with a diameter of 2-9 $\mathrm{mm}$, taking into account the location, and / or total 
volume $>10 \mathrm{~mL}^{3}$, through transvaginal ultrasound examination, (2) Oligo and / or anovulation, (3) biochemical / clinical evidence of hyperandrogenism. ${ }^{1,2}$ In the United States, the prevalence of women with PCOS ranges from 4 to $6 \% .{ }^{3}$ Meanwhile in the Indonesian study, PCOS is found in $11 \%$ of the population. $^{4}$

Infertility is a complaint that is quite often encountered on PCOS patients with a prevalence of complaints of $90-95 \% .{ }^{4}$ Based on the Indonesian Consensus for Infertility, infertility is defined as the failure of a partner to get pregnant for at least 12 months of regular sexual intercourse without contraception (primary infertility) or the inability of a person to have a child or maintain his pregnancy (secondary infertility). ${ }^{4}$ Infertility is an important issue, because it heavily affect quality of life.

PCOS patients have more severe problem due to in addition to the infertility suffered, a higher prevalence of pregnancy complications are found, such as increased prevalence of abortion in PCOS patients with infertility management (artificial insemination, in vitro fertilization) due to insulin resistance, higher prevalence of preeclampsia due to vascular and metabolic disorders occurring, as well as increased risk of preterm birth due to multiple pregnancy which is more common in patients with PCOS. ${ }^{3}$

One method of managing infertility is in vitro fertilization (IVF) technique. IVF is an egg fertilization process with sperm cells outside the uterus (thus, in vitro). Based on data from the International Committee for Monitoring Assisted Reproductive Technologies (ICMART) in 2007, there has been an increase in infertility cases in women with PCOS undergoing assisted reproductive therapy such as ovulation induction or in vitro fertilization (IVF).

Data from our hospital in 2014 stated that in PCOS patients, in addition to the low success rate of fertilization, the complications occurring are also quite high. Complications mentioned were low birth weight, abortion, postpartum hemorrhage, and other complications. However, there was yet a study of obstetrics complications in PCOS patients undergoing IVF treatment in Indonesia.

This study aims to examine the relationship between PCOS and obstetrics complications in women undergoing IVF program. The expected outcome is that this study can detect early possible obstetric complications that occur in PCOS patients participating in the IVF program so that they can be observed and treated early.

\section{Methods}

This is an observational analytic study using retrospective cohort method determined to assess the difference in obstetrics complications between PCOS and non-PCOS patients undergoing IVF. The diagnosis of PCOS was established using Rotterdam Criteria. Obstetrics complications in this study were defined as preterm birth, ectopic pregnancy, and abortion.

This study used $5 \%$ error bound and $95 \%$ confidence interval limit, power of the test considered to be $90 \%$. The inclusion criteria for this research were all women undergoing IVF program at dr. Cipto 
Mangunkusumo National General Hospital, Jakarta, Indonesia during the course of the study aged at least 18 years old. Meanwhile, the exclusion criteria of this study were women with other obstetrics and gynecology diseases besides PCOS.

The study was approved by the Faculty of Medicine, University of Indonesia. All human studies had been approved by the Research Ethics Committee with ethical clearance number 87/UN2F1/ETIK/2019. All patients who were included in this study had given their informed consent prior to their inclusion in the study.

Collected data were then analyzed using SPSS for Macintosh ver. 20. Characteristics of subjects were analyzed descriptively. Bivariate analysis was done using chi-square method or Fisher test if the requirements were not met. Multivariate test was done using cox regression analysis in order to determine the risk ratio $(\mathrm{RR})$ of risk factors.

\section{Results}

A total of 2,965 patients met the inclusion criteria, consisting of $320(10.8 \%)$ PCOS patients and 2645 (89.2\%) non-PCOS subjects. However, clinical pregnancy was only achieved by 92 (28.75\%) of PCOS patients and 459 (17.35\%) of non-PCOS patients. Among those with clinical pregnancy, patients with other gynecological complications were excluded from the study. Hence, a total of 72 PCOS subjects and 283 non-PCOS subjects were analyzed in this study. Univariate test was performed to assess the general characteristics of subjects (Table 1) 
Table 1

General Characteristics of Subjects

\begin{tabular}{|c|c|c|c|}
\hline Variables & $\begin{array}{l}\text { PCOS } \\
(n=72)\end{array}$ & $\begin{array}{l}\text { Non-PCOS } \\
(n=283)\end{array}$ & $\mathbf{p}$ \\
\hline \multicolumn{4}{|l|}{ Age } \\
\hline$<40$ years & 69 (20.3) & 271 (79.7) & 0.978 \\
\hline$\geq 40$ years & $3(20.0)$ & $12(80.0)$ & \\
\hline \multicolumn{4}{|l|}{ Obesity } \\
\hline Yes $(>24.9 \mathrm{~kg} / \mathrm{m} 2)$ & $51(34.2)$ & $98(65.8)$ & $<0.001$ \\
\hline No $(\leq 24.9 \mathrm{~kg} / \mathrm{m} 2)$ & $21(10.2)$ & $185(89.8)$ & \\
\hline \multicolumn{4}{|l|}{ Infertility type } \\
\hline Primary & $45(15.0)$ & 255 (85) & $<0.001$ \\
\hline Secondary & $27(40.1)$ & $28(50.9)$ & \\
\hline \multicolumn{4}{|l|}{ Infertility duration } \\
\hline$\geq 10$ years & $7(21.5)$ & $49(87.5)$ & 0.024 \\
\hline$<10$ years & 65 (21.7) & $234(78.3)$ & \\
\hline \multicolumn{4}{|l|}{ AMH level } \\
\hline$<1$ & $0(0)$ & $34(100)$ & $<0.001$ \\
\hline $1-4$ & $8(4.2)$ & $184(95.8)$ & \\
\hline$>4$ & $64(49.6)$ & $65(50.4)$ & \\
\hline \multicolumn{4}{|l|}{ IVF method } \\
\hline ICSI & $38(12.6)$ & $264(87.4)$ & $<0.001$ \\
\hline FET & $34(64.2)$ & $19(35.9)$ & \\
\hline \multicolumn{4}{|l|}{ rFSH dosage } \\
\hline$\geq 1800$ & $32(12.1)$ & 232 (87.9) & $<0.001$ \\
\hline$<1800$ & $40(44.0)$ & $51(56.0)$ & \\
\hline \multicolumn{4}{|l|}{ rLH dosage } \\
\hline$>193$ & $40(17.1)$ & 194 (82.9) & 0.038 \\
\hline$<193$ & $32(26.5)$ & $89(73.6)$ & \\
\hline Stimulation duration & & & \\
\hline
\end{tabular}




\begin{tabular}{|clll|}
\hline Variables & $\begin{array}{l}\text { PCOS } \\
(\mathbf{n = 7 2})\end{array}$ & $\begin{array}{l}\text { Non-PCOS } \\
(\mathbf{n = 2 8 3})\end{array}$ & $\mathbf{p}$ \\
\hline$\geq 10$ days & $18(10.2)$ & $158(89.8)$ & $<0.001$ \\
\hline$<10$ days & $54(30.2)$ & $125(69.8)$ & \\
\hline Endometrial thickness & & & \\
\hline 12 & $45(23.2)$ & $149(76.8)$ & 0.134 \\
\hline 12 & $27(16.8)$ & $134(83.2)$ & \\
\hline Cleavage & & & \\
\hline$\leq 6$ & $8(4.8)$ & $160(95.2)$ & $<0.001$ \\
\hline$>6$ & $64(34.2)$ & $123(65.8)$ & \\
\hline
\end{tabular}

Knowing the characteristics of the subjects, obstetrics complications suffered by subjects were also noted on Table 2.

Table 2

Obstetrics Complications of Subjects

\begin{tabular}{|lll|}
\hline Obstetrics Complications & PCOS & Non-PCOS \\
\hline Preterm birth & $2(2.78)$ & $17(6.01)$ \\
\hline Ectopic pregnancy & $1(1.39)$ & $1(0.35)$ \\
\hline Abortion & $7(9.72)$ & $15(5.30)$ \\
\hline
\end{tabular}

Among all PCOS patients, abortion is the most prevalent obstetrics complication (9.72\%), while in nonPCOS patients preterm birth is the most prevalent one (6.01\%). In order to determine the relationship between PCOS and abortion, bivariate analysis was done. The result can be found on Table 3 .

Table 3

Relationship between PCOS and Abortion in Subjects

\begin{tabular}{|lllll|}
\hline PCOS & \multicolumn{3}{l}{ Abortion } & \multicolumn{2}{c|}{ RR $(95 \% \mathrm{Cl})$} & p-value \\
\cline { 2 - 4 } & $(+)$ & $(-)$ & & \\
\hline Yes & $7(9.7)$ & $15(5.3)$ & 1.63 & 0.165 \\
\cline { 1 - 4 } No & $65(90.3)$ & $268(94.7)$ & $(0.85-3.12)$ & \\
\hline
\end{tabular}

In order to determine the independent relationship between clinical characteristic variables and PCOS with abortion in subjects, multivariate analysis using cox regression analysis was done. We also did 
interaction analysis on PCOS and various clinical characteristics to abortion in IVF subjects. The results can be found on Table 4.

Table 4

Multivariate Analysis between PCOS and its Interaction with Abortion

\begin{tabular}{|lllll|}
\hline Variables & RR & Beta & $95 \% \mathrm{Cl}$ & P-value \\
\hline PCOS & 0.90 & -0.10 & $0.22-3.65$ & 0.885 \\
\hline IVF & 0.67 & -0.41 & $0.18-2.45$ & 0.540 \\
\hline Cleavage & 0.89 & -1.12 & $0.32-2.46$ & 0.821 \\
\hline Cleavage \& PCOS & 8.55 & 2.15 & $1.20-61.15$ & 0.033 \\
\hline
\end{tabular}

Moreover, hazard ratio of interaction between PCOS and embryonal cleavage was calculated with the occurrence of abortion in subjects, with results on Table 5.

Table 5

Relationship between PCOS and Embryonal Cleavage Interaction with Abortion

\begin{tabular}{|llll|}
\hline PCOS & RR & $95 \% \mathrm{Cl}$ & P-value \\
\hline Cleavage $<6$ & 7.32 & $2.10-25.45$ & 0.002 \\
\hline Cleavage $\geq 6$ & 0.96 & $0.26-3.53$ & 0.949 \\
\hline
\end{tabular}

\section{Discussion}

Based on the results of this study the number of women with PCOS who underwent the IVF program at Dr. Cipto Mangunkusumo National General Hospital in 2013-2019 was 320 people or $10.8 \%$, of whom clinical pregnancy was found in 92 subjects with PCOS or $28.75 \%$. the results of this study were lower than the study conducted by Chen et al in China with $71.5 \%$ of clinical pregnancies in patients with PCOS and $65.9 \%$ of clinical pregnancies in obese PCOS patients. ${ }^{5}$ Similar results were obtained by Diamant et al with $8 \%$ success of IVF in PCOS patients compared to $54.9 \%$ success in non PCOS patients. ${ }^{6}$

In this study, a higher obesity rate was found in patients with PCOS. In accordance with previous studies, excessive body weight to obesity is indeed one of the characteristics found in patients with PCOS. On the one hand, patients with PCOS with ideal body weight already have insulin resistance that is exacerbated during the pregnancy process. ${ }^{3}$ On the other hand, excessive body weight will increase the likelihood of PCOS phenotype emergence while worsening metabolic and reproductive disorders such as insulin resistance, hyperandrogenemia, and increase the risk of infertility. ${ }^{1}$ Previous studies have suggested that weight loss of $2-5 \%$ in obese patients with PCOS will increase insulin sensitivity and reduce the 
symptoms of menstrual disorders, so weight loss and lifestyle changes are the first-line therapy for patients with PCOS. ${ }^{4}$

In the PCOS group, high AMH levels ( $>4 \mathrm{ng} / \mathrm{mL}$ ) were obtained compared to the group without PCOS (1$4 \mathrm{ng} / \mathrm{mL})$. The differences between groups were statistically significant $(p<0.001)$. This is consistent with previous studies which assess that patients with PCOS had higher follicular counts, so they have a much higher blood AMH level compared to patients without PCOS. ${ }^{7,8} \mathrm{AMH}$ in the IVF program is used as one of the examinations ovarian reserve before the start of the IVF program with the highest sensitivity and specificity values. ${ }^{4}$

In this study, $9.72 \%$ of subjects with PCOS experienced abortion. Previous studies have shown that early pregnancy loss (EPL - fetal death in the first trimester of pregnancy) is experienced by $10-15 \%$ of normal women and $30-50 \%$ of women with PCOS. ${ }^{9}$ However, there are no studies that show differences in the rate of fetal death in early pregnancy in patients undergoing IVF therapy in both patients with PCOS and patients without PCOS. ${ }^{3}$ Based on some previous studies, an increased possibility of abortion in patients with PCOS might be due to increased embryos polypoid, hypofibrinolysis due to increased plasminogen activator inhibitors, and insulin resistance. ${ }^{10,11}$

In this study, an interaction was found between PCOS with cleavage to the occurrence of abortion as an outcome of pregnancy. The risk of women with PCOS to experience abortion if implanted is smaller than 6 times the division, the risk of abortion will increase 7.32 times compared to women with PCOS that are implanted greater than 6 times the division. However, there is no direct relationship between PCOS and the incidence of abortion in patients undergoing IVF.

Based on research conducted by Papanikolaou et al, the rate of cleavage more than 4 times has a higher rate of advanced births compared to embryos with smaller cleavage rates (OR 2.78 IK95\% 1.45-5.34). ${ }^{12}$ lower associated with lower LH levels so that the maturation rate is worse than patients with higher LH levels. However, in patients with PCOS, the LH level needs to be adjusted so that it does not cause OHSS (Ovarian Hyperstimulation Syndrome). ${ }^{12}$

\section{Conclusions}

It is concluded in this study that there was no relationship between PCOS and obstetrics outcome in women undergoing IVF program. Adopting the result of this research, IVF program represents one of the feasible managements of infertility problem in PCOS patients, without any added risk of obstetric complications.

\section{Abbreviations}

$\mathrm{AMH}$

anti Mullerian hormone 
$\mathrm{Cl}$

confidence interval

ICMART

International Committee for Monitoring Assisted Reproductive Technologies

IVF

In vitro fertilization

PCOS

Polycystic Ovarian Syndrome

$\mathrm{rFSH}$

recombinant follicle stimulating hormone

$\mathrm{rLH}$

recombinant luteinizing hormone

RR

Risk Ratio

\section{Declarations}

\section{ETHICS APPROVAL AND CONSENT TO PARTICIPATE}

The study was approved by the Faculty of Medicine, University of Indonesia. All human studies had been approved by the Research Ethics Committee with ethical clearance number 87/UN2F1/ETIK/2019. All patients who were included in this study had given their informed consent prior to their inclusion in the study.

\section{CONSENT FOR PUBLICATION}

There was no individual person's data presented in this study.

\section{AVAILIBILITY OF DATA AND MATERIALS}

The datasets used and/or analyzed during the current study are available on Synapse Repository on https://www.synapse.org/\#!Synapse:syn22272662/wiki/604750.

\section{CONFLICT OF INTEREST}

Authors declare that there is no conflict of interest in this study.

\section{AUTHOR'S CONTRIBUTIONS}


MR was the leading researcher for this study, with major contribution for statistical analysis for the study.

PY was a major contributor in writing the manuscript, enumerator, and contributor in statistical analysis

MM and AKH executed in vitro fertilization and follow up examination for the study

GP analyzed in vitro fertilization result.

BW provided supervision and contributed in discussion.

AH contributed in analyzing the result

\section{FUNDING STATEMENT}

All of the funding for this research was financed by authors.

\section{ACKNOWLEDGEMENTS}

Authors would like to express sincere gratitude to all participating patients who willingly support this study.

\section{References}

1. Norman RJ, Dewailly D, Legro RS, Hickey TE. Polycystic ovary syndrome. Lancet. 2007;370(9588):685-97.

2. Bako AU, Morad S, Atiomo W. Polycystic ovary syndrome: An oveview. Reviews in Gynaecological Practice. 2005;5:115-22.

3. Palomba S, de Wilde MA, Falbo A, Koster MP, La Sala GB, Fauser BC. Pregnancy complications in women with polycystic ovary syndrome. Hum Reprod Update. 2015;21(5):575-92.

4. Himpunan Endokrinologi Reproduksi dan Fertilitas Indonesia (HIFERI). Perhimpunan Fertilisasi In Vitro Indonesia (PERFITRI). Konsensus Penanganan Infertilitas. Jakarta: HIFERI-PERFITRI; 2013. 75 p.

5. Chen R, Chen S, Liu M, He H, Xu H, Liu H, et al. Pregnancy outcomes of PCOS overweight/obese patients after controlled ovarian stimulation with the $\mathrm{GnRH}$ antagonist protocol and frozen embryo transfer. Reprod Biol Endocrinol. 2018;16:36.

6. Diamant YZ, Rimon E, Evron S. High incidence of preeclamptic toxemia in patients with polycystic ovarian disease. Eur J Obstet Gynecol Reprod Biol. 1982;14:199-204.

7. Wiweko B, Maidarti M, Priangga MD, Shafira N, Fernando D, Sumapraja K, et al. Anti-mullerian hormone as a diagnostic and prognostic tool for PCOS patients. J Assist Reprod Genet. 2014;31(10):1311-6. 
8. De Frene V, Vansteelandt S, T'Sjoen G, Gerris J, Somers S, Vercruysse L, et al. A retrospective study of the pregnancy, delivery and neonatal outcome in overweight versus normal weight women with polycystic ovary syndrome. Hum Reprod. 2014;29(10):2333-8.

9. Araki T, Elias R, Rosenwaks Z, Poretsky L. Achieving a successful pregnancy in women with polycystic ovary syndrome. Endocrinol Metab Clin North Am. 2011;40(4):865-94.

10. Barbieri RL. Female Infertility. In: Strauss JF, Barbieri RL, editors. Yen And Jaffe's Reproductive Endocrinology: Physiology, Pathophysiology, And Clinical Management. 7th ed: Elsevier; 2014. p. 512 $-37$.

11. Falbo A, Rocca M, Russo T, D'Ettore A, Tolino A, Zullo F, et al. Changes in androgens and insulin sensitivity indexes throughout pregnancy in women with polycystic ovary syndrome (PCOS): relationships with adverse outcomes. J Ovarian Res. 2010;3:23.

12. Papanikolaou EG, D'haeseleer E, Verheyen G, Velde HV, Camus M, Sterirteghem AV, et al. Live birth rate is significantly higher after blastocyst transfer than after cleavage-stage embryo transfer when at least four embryos are available on day 3 of embryo culture. A randomized prospective study. Human Reprod. 2005;20(11):3198-203. 